\title{
Smartphone Addiction and Associated Factors among Postgraduate Students in an Arabic Sample: A Cross-sectional Study.
}

\section{Asem Alageel ( $\sim$ asemalageel@yahoo.com )}

College of Medicine, Al-Imam Muhammad Ibn Saud Islamic University (IMSIU)

\section{Rayyan Alyahya}

College of Medicine, Al-Imam Muhammad Ibn Saud Islamic University (IMSIU)

\section{Yasser Bahatheq}

College of Medicine, Al-Imam Muhammad Ibn Saud Islamic University (IMSIU)

Norah Alzunaydi

Alamal Complex for Mental Health

\section{Raed Alghamdi}

College of Medicine, Al-Imam Muhammad Ibn Saud Islamic University (IMSIU)

Nader Alrahili

College of Medicine, Al-Imam Muhammad Ibn Saud Islamic University (IMSIU)

\section{Roger Mclntyre}

University of Toronto

Michelle lacobucci

University Health Network

\section{Research Article}

Keywords: Smartphone, Depression, Postgraduate, ADHD, Insomnia, Smoking

Posted Date: January 25th, 2021

DOI: https://doi.org/10.21203/rs.3.rs-135808/v1

License: (1) (1) This work is licensed under a Creative Commons Attribution 4.0 International License.

Read Full License 


\section{Abstract}

\section{Background:}

Smartphone addiction and other behavioral addictions have been established to accompany social, physical, and mental health issues. In this article, we will be investigating the prevalence of smartphone addiction among postgraduate students as well as assessing its relationship to social demographics, depression, ADHD, and nicotine dependence.

\section{Objectives:}

- The prevalence of smartphone addiction among middle eastern postgraduate students.

- Ascertain the associated factors of smartphone addiction.

- Measure the incidence of MDD, ADHD, insomnia, and nicotine addiction among postgraduate students with smartphone addiction.

\section{Methods:}

A Cross-sectional online survey, a self-questionnaire is divided into six sections; Socio-demographics, the Smartphone Addiction Scale (SAS) Patient Health Questionnaire for Depression (PHQ9). Athens Insomnia Scale (AIS) the Fagerstrom Test for Cigarette Dependence Questionnaire (FTCd) and the Adult ADHD SelfReport Scale (ASRS-v1.1)

\section{Results:}

$51.0 \%$ of the participants had smartphone addiction. There's a significant association between high smartphone use and MDD ( $p=0.001) .41 .5 \%$ of smokers are addicted to smartphones $(p=0.039)$. Smartphone addicts have about two times the risk of developing insomnia ( $O R=2.113)(P=0.013)$. Smartphone addicts had a significant risk of developing ADHD symptoms $(O R=2.712)(P<0.001)$.

\section{Conclusion:}

Confirming several studies, we found a positive association between Insomnia, Depression, Adult ADHD, and Smartphone addiction. Therefore, we encourage the scientific community to study the impacts of smartphone addiction and the mental health of post-graduate students.

\section{Introduction:}

Smartphones are handheld mobile devices with an internet connection and the ability to run additional software (Email, social media, webbrowser..etc). The first smartphone was produced in 1992, but the term "smartphone" was designated in 1995 ever since the functions of a smartphone evolved to include more than communications. It now includes, but is not limited to, entertainment, social media, health 
monitoring, productivity, and utility functions such as day planners, and text and photo editing all in one handheld device. With this wide array of functionalities built into smartphones, researchers can now observe the increasing number of smartphone users. In 2017 Google announced that they had reached 2 billion active users, and in 2019 that the number had reached 2.5 billion ${ }^{25}$. Additionally, in 2019 Apple announced 900 million active users ${ }^{40}$. In 2019, Google and Apple collectively announced that there were 3.4 billion people using smartphones. These numbers do not consider the smartphone users who do not use Apple or Google products.

According to the American psychiatric association, addiction is "A complex condition, a brain disease that is manifested by compulsive substance use despite harmful consequences." ${ }^{4}$ Regardless of whether the addiction is substance or behavior related, there are five elements of addiction ${ }^{54}$. The first element is feeling different, which includes feeling relatively uncomfortable, lonely, restless, or incomplete ${ }^{30}$. The second element of addiction is the preoccupation with the behavior, excessive thoughts about and desire to perform a behavior, excessive time spent to plan and engage in the behavior, and possibly recover from its effects, and less time spent on other activities ${ }^{11}$ despite potentially diminishing appetitive effects ${ }^{48,49}$. Temporary Satiation is the third element of addiction, after acute engagement in an addictive behavior, some period of time may occur in which urges are not operative, addiction craving is "shut down", only to return soon $21,44,41$. The fourth element is Loss of Control, wherein many people who claim to be struggling with addiction experience feeling compelled to the addiction, a loss of control, and in some cases, neglecting essential self-care, which suggests a loss of will ${ }^{43}$. The final element is negative consequences which means continuing to engage in the addictive behavior after suffering numerous negative consequences. This last component of addiction has often been a criterion of dependence on the addictive behavior ${ }^{24}$.

"Smartphone addiction" could be considered as one form of technological addictions. Generally, similar to internet addiction, smartphone addiction consists of four main components: compulsive behaviors, tolerance, withdrawal, and functional impairment ${ }^{7}$. In a study completed among 2367 university students in Riyadh, results indicated that $27.2 \%$ of participants stated that they spent more than 8 hours per day using their smartphones ${ }^{3}$. In another study done on 688 Lebanese university students, $49 \%$ reported excessive smartphone use ( $\geq 5$ hours/weekday), 9

Major Depressive Disorder (MDD) is a mental illness portrayed by hindering changes to the way a person thinks, acts, and feels. It causes feelings of sadness and bitterness and a loss of enthusiasm when partaking in activities the individual once enjoyed. MDD can present with a wide variety of symptoms, including lack of appetite, fatigue, trouble sleeping (e.g., Insomnia), feelings of guilt, and thoughts of suicide. Contingent upon the severity of MDD, it can be associated with a degree of cognitive dysfunction affecting the capacity to perform everyday home and work activities by prompting an assortment of physical and emotional issues ${ }^{4,42,12}$. MDD seems to have a close relationship with addiction and substance abuse. Two epidemiological studies in 1990 and 1994 have showcased evidence that mood disorders increase the risk of Substance Use Disorders (SUD) ${ }^{47,33}$. One literature review examined the 
relationship between Alcohol Use Disorders (AUD) and MDD and found a correlation between the two, where AUD would double the risk of developing MDD and vice versa ${ }^{8}$. Mood disorders and SUD comorbidity lowers the prognosis and treatment outcome for each problem ${ }^{46}$. However, there is evidence to suggest that the successful treatment of a comorbid mood disorder would decrease craving and substance abuse ${ }^{13}$. Furthermore, the correlations are not exclusive to substance addiction and several studies have concluded that behavioral addictions (such as internet and smartphone addiction) can be associated with MDD ${ }^{38,2}$.

Insomnia is defined as a subjective perception of difficulty falling or staying asleep; it can have acute episodes of one night or last chronically for up to several weeks or even months, it is associated with decreased mental and physical Health-Related Quality of Life (HRQoL) scores ${ }^{50}$, and psychiatric illness ${ }^{28}$. Furthermore, though indirectly, it is associated with smartphone overuse ${ }^{14}$.

Attention-deficit hyperactivity disorder (ADHD) is a neurodevelopmental disorder with onset in childhood that may last into adulthood characterized by hyperactivity, impulsiveness, or inattentiveness, and often all three symptoms (DSM-IV-TR (APA, 2000) that interfere or affect the quality of social, academic or occupational performance or development ${ }^{5} \mathrm{~A}$ study in different countries in America, Europe, and the Middle East, showed average adult ADHD prevalence of 3.4\% with a higher percentage of high economic countries (4.2\%) compared to poor economic countries (1.9\%) ${ }^{20}$. Adults with ADHD have a significantly high chance of suffering from depressive, antisocial personality, anxiety, and substance use disorders ${ }^{18}$.

Past studies have been done on the prevalence of smartphone addiction and its relationship to mental and physical issues, be that as it may, these investigations showcased a portion of the components identified with smartphone addiction. In contrast, numerous elements, such as ADHD or nicotine addiction, were left uninvestigated. The objective of this study is to discover the level of relationship between Smartphone addiction and different elements including, but not limited to, MDD, Nicotine Dependence, Quality of life, and Sleep to locate standard variables among postgraduates that will ideally prompt awareness and knowledge about smartphone addiction on society while surveying the level of its mental impacts.

The goal of this examination is to distinguish the prevalence of smartphone addiction among postgraduate students. Because of the expanded apparent pressures that these individuals experience ${ }^{45}$, we believe that Postgraduate students are an especially vulnerable populace to smartphone addiction. Postgraduate students will, in general, use smartphones to communicate, access data they need in school as well as entertainment. As far as we know, no present investigations are recognizing the prevalence of smartphone addiction among Arabian middle eastern postgraduate students. In this article, we will be investigating the prevalence of smartphone addiction among postgraduate students as well as assessing its relationship to social demographics, depression, ADHD, and nicotine dependence.

\section{Methods:}


A cross-sectional online survey filled by 558 Arabic participants, was sent via email and social media accounts for postgraduate education (Twitter, Facebook, and WhatsApp) to post-secondary students. Participants were considered in the study if they were Postgraduates and smartphone users. Postgraduate students from 187 different universities participated in the study. Participants were studying in different countries around the world, including Saudi Arabia, Jordan, Egypt, Kuwait, Algeria, Bahrain, Iraq, Lebanon, Afghanistan, Ethiopia, Fiji, Cyprus, Australia, England, United States, and Canada. We excluded fifty-two students from the study due to incomplete questionnaires leaving us with a total of 506 participants. This study was approved by the Institutional Review Board (IRB) of Imam Mohammad ibn Saud Islamic University in Riyadh, Saudi Arabia. Furthermore, Informed consent was obtained from all participants through a statement of agreement at the beginning of each questionnaire, all methods were thoroughly explained to each participant and performed in accordance with the relevant guidelines, regulations and the WMA Declaration of Helsinki.

The online survey consisted of 43 questions and took approximately 5 to 10 minutes to complete; we divided it into six parts. The first part was concerned with socio-demographic information (such as age and gender). The second and third parts included the Arabic-validated versions of the Smartphone Addiction Scale (SAS) ${ }^{51}$ and the Patient Health Questionnaire for Depression (PHQ9) ${ }^{1}$. The fourth part used Athens Insomnia Scale (AIS) to assess the quality of sleep ${ }^{52}$, and the fifth section concerned nicotine dependence and implemented the Fagerstrom Test for Cigarette Dependence Questionnaire (FTCd) for assessment ${ }^{32}$. Finally, the sixth section was the Adult ADHD Self-Report Scale (ASRS-v1.1) ${ }^{34}$

Smartphone addiction was measured using the arabic version of Smartphone Addiction Scale (SAS). SAS is a self-diagnosis scale that was modified from K-scale which is a scale to assess Internet addiction for juveniles. SAS consists of 33 items with 6 subscales, which are daily life disturbance, positive anticipation, withdrawal, cyberspace-oriented relationship, overuse, and tolerance ${ }^{39}$. Items are scored on a six-point likert scale as follows: strongly disagree (1), disagree (2), weakly disagree (3), weakly agree (4), agree (5), strongly agree (6). The sum of the six subscales refers to SAS score with a range of 33 to 198. Higher score means higher addictive behaviour with smartphones ${ }^{39}$. Data factorability for the Arabic version of SAS was confirmed using Kaiser-Meyer-Olkin (KMO) test of sampling adequacy with a resulting value of 0.94 and supported with Bartlett's test of sphericity to verify the suitability of data for factor analysis which showed a significant value of $p<0.01^{51}$. The internal consistency for Arabic SAS was calculated using Cronbach's alpha with a value of $a=0.94{ }^{51}$. In this study, we grouped participants who scored 116 or more in SAS in the high smartphone usage group and participants who scored less were put in a low smartphone usage.

The second part of the questionnaire was the Patient Health Questionnaire for depression (PHQ9), a selfreport questionnaire designed to assess the level of depression over the last two weeks, where higher scores indicated a higher chance of depressio ${ }^{37}$. We used a validated and translated version to assess our Arabic population; it had internal consistency reliability of 0.857 calculated using Cronbach's alpha ${ }^{1}$. We used the cut-off point of 10 for clinically significant depression; we then further classified the 
depressed participants to clinically significant, moderately severe, and severe. We have considered those who scored between 10-14 to have clinically significant depression, scores that range between 15-19 are moderately severe depression, and severe depression for participants who scored more than 20.

Participants who scored $15+$ warranted active treatment ${ }^{37}$.

Athens Insomnia Scale (AIS) was used to measure sleep quality, the English version had an optimum specificity of $85 \%$ and sensitivity of $93 \%{ }^{52}$, it assesses sleep quality over the last month, using a 4 point system of 0 to 3 , where zero means no insomnia symptoms and three means more acute sleep difficulties. In our study, we considered any participant with a score of 6 or more to have insomnia. We used an Arabic translated version by Toronto Sleep Clinics, an English-speaking healthcare professional whose mother tongue is Arabic translated the scale from English to Arabic, and using the same approach as the first translation, another translator did back-translation to English, a few English-speaking translators reviewed any problematic contextual discrepancies. However, it is yet to be tested for validity.

The fifth part included Fagerstrom Test for Cigarette Dependence Questionnaire (FTCd) a 6-item questionnaire used to measure the nicotine dependence associated with cigarette smoking, it uses a 10 point system, wherein we considered those who score less than four to be minimally dependent, 4- 6 were moderately dependent, 6-10 were highly dependent. FTCd was found to be moderately reliable on an Arabic sample and was valued 0.68 on the Cronbach alpha coefficien ${ }^{32}$.

We used the validated arabic version Adult ADHD Self-Report Scale (ASRS-v1.1), a 6-item screening tool for attention-deficit/hyperactivity disorder (ADHD) to assess Adult ADHD, it was proven to be a reliable tool, with a sensitivity of (68.7\%), and specificity of (99.5\%), two-thirds of clinical cases of ADHD scored $4-6^{34}$

\section{Results:}

The total number of participants in this study was 506, 158 (31.23\%) males, and $348(68.77 \%)$ females. $9.41 \%$ of participants were between 21 to 24 years old, $35.88 \%$ were between 25 to 29 years of age $(P=$ 0.007 ), $44.51 \%$ were from 30 to 39 years old, and $10.20 \%$ of the participants were 40 years old and above. $46.18 \%$ of our respondents were single, $50.68 \%$ were married, and $3.13 \%$ were divorced. The majority of participants did not have any children at $56.19 \%$. The participants were taking different majors, the majority of participants at $49.32 \%$ were partaking courses in Humanities/Social sciences, $12.72 \%$ were studying Biological/Physical Sciences, $12.92 \%$ were in Engineering, and 25.05\% were from other unspecified majors. $67.72 \%$ of the participants were studying for a Master's degree; on the other hand, $32.28 \%$ were preparing their Ph.D. First-year students were $26.39 \%$, students in their second year were $32.08 \%$, third-year students were $20.40 \%$, while $10.30 \%$ of the students were in their fourth year and the same number of students were in their fifth year of studies. $33.86 \%$ of our participants are studying abroad, while $66.14 \%$ of students were studying in their country of origin. (Table 1) [Table 1] 
Table 1

Characteristics of the participants

\begin{tabular}{|c|c|c|c|}
\hline & & Number & $\%$ \\
\hline \multirow[t]{2}{*}{ Gender } & Male & 158 & 31.23 \\
\hline & Female & 348 & 68.77 \\
\hline \multirow[t]{4}{*}{ Age } & $21-24$ & 48 & 9.41 \\
\hline & $25-29$ & 183 & 35.88 \\
\hline & $30-39$ & 227 & 44.51 \\
\hline & $>=40$ & 52 & 10.20 \\
\hline \multirow[t]{3}{*}{ Marital status } & Single & 236 & 46.18 \\
\hline & Married & 259 & 50.68 \\
\hline & Divorced & 16 & 3.13 \\
\hline \multirow[t]{4}{*}{ Number of children } & 0 & 286 & 56.19 \\
\hline & 1 & 67 & 13.16 \\
\hline & 2 & 64 & 12.57 \\
\hline & $>=3$ & 92 & 18.07 \\
\hline \multirow[t]{2}{*}{ Educational level } & Master & 342 & 67.72 \\
\hline & $\mathrm{PhD}$ & 163 & 32.28 \\
\hline \multirow[t]{5}{*}{ Academic year } & First & 136 & 26.93 \\
\hline & Second & 162 & 32.08 \\
\hline & Third & 103 & 20.40 \\
\hline & Fourth & 52 & 10.30 \\
\hline & Fifth & 52 & 10.30 \\
\hline \multirow[t]{2}{*}{ Being outside the country } & Yes & 173 & 33.86 \\
\hline & No & 338 & 66.14 \\
\hline
\end{tabular}

According to the Smartphone Addiction Scale, $51.0 \%$ of the participants appear to be high smartphone users, while $49.0 \%$ are low smartphone users. (Table 2 ) 
Table 2

Prevalence of Depression and Anxiety disorders

\begin{tabular}{|lcc|}
\hline & Number & $\%$ \\
\hline Depression & 598 & 59.5 \\
\hline Moderate to Severe Depression & 133 & 13.2 \\
\hline Severe Depression & 143 & 14.2 \\
\hline Clinically significant Anxiety Disorder & 552 & 54.9 \\
\hline Severe Anxiety Disorder & 237 & 23.6 \\
\hline
\end{tabular}

Statistical analysis showed no significant relationship between smartphone use and most sociodemographic characteristics which include: gender, marital status, number of children, studies majors, educational level, academic year, being outside the country, participants monthly income, family monthly income, GPA, and the number of published papers. However, it showed a statistically significant relationship between smartphone use and the population's age $(p=0.026)$. [Table 3 ]

In this research, $\mathrm{P}$ values of $₫ 0.05$ were considered statistically significant. Regarding high-smartphone use and age; $35.4 \%$ (17) of participants between the ages of 21-24 years of age, $57.3 \%(105)$ of people between the ages of $25-29,51.5 \%(117)$ of people of the age $30-39$, and $42.3 \%(22)$ of those above 40 years of age scored high on the SAS scale. (Table 3) [Table 3] 
Table 3

Relation between smartphone addiction and Characteristics of the participants

\begin{tabular}{|c|c|c|c|c|c|c|}
\hline & & \multicolumn{2}{|c|}{$\begin{array}{l}\text { High smartphone use } \\
\text { group (261) }\end{array}$} & \multicolumn{2}{|c|}{$\begin{array}{l}\text { Low smartphone use } \\
\text { group (251) }\end{array}$} & \multirow[t]{2}{*}{$\begin{array}{l}P \\
\text { value }\end{array}$} \\
\hline & & Number & $\%$ & Number & $\%$ & \\
\hline \multirow[t]{2}{*}{ Gender } & Male & 88 & 33.8 & 70 & 28.5 & \multirow[t]{2}{*}{0.191} \\
\hline & Female & 172 & 66.2 & 176 & 71.5 & \\
\hline \multirow[t]{4}{*}{ Age } & $21-24$ & 17 & 6.5 & 31 & 12.4 & \multirow[t]{4}{*}{$0.026 *$} \\
\hline & $25-29$ & 105 & 40.2 & 78 & 31.3 & \\
\hline & $30-39$ & 117 & 44.8 & 110 & 44.2 & \\
\hline & $>=40$ & 22 & 8.4 & 30 & 12.0 & \\
\hline \multirow[t]{3}{*}{ Marital status } & Single & 115 & 44.1 & 121 & 48.4 & \multirow[t]{3}{*}{0.268} \\
\hline & Married & 135 & 51.7 & 124 & 49.6 & \\
\hline & Divorced & 11 & 4.2 & 5 & 2.0 & \\
\hline \multirow[t]{4}{*}{ Number of children } & 0 & 147 & 56.3 & 139 & 56.0 & \multirow[t]{4}{*}{0.867} \\
\hline & 1 & 37 & 14.2 & 30 & 12.1 & \\
\hline & 2 & 31 & 11.9 & 33 & 13.3 & \\
\hline & $>=3$ & 46 & 17.6 & 46 & 18.5 & \\
\hline \multirow[t]{2}{*}{ Educational level } & Master & 180 & 69.2 & 162 & 66.1 & \\
\hline & $\mathrm{PhD}$ & 80 & 30.8 & 83 & 33.9 & \\
\hline \multirow[t]{5}{*}{ Academic year } & First & 80 & 30.8 & 56 & 22.9 & \multirow[t]{5}{*}{0.349} \\
\hline & Second & 80 & 30.8 & 82 & 33.5 & \\
\hline & Third & 48 & 18.5 & 55 & 22.4 & \\
\hline & Fourth & 27 & 10.4 & 25 & 10.2 & \\
\hline & Fifth & 25 & 9.6 & 27 & 11.0 & \\
\hline \multirow[t]{2}{*}{ Being outside the country } & Yes & 94 & 36.2 & 79 & 31.5 & \multirow[t]{2}{*}{0.264} \\
\hline & No & 166 & 63.8 & 172 & 68.5 & \\
\hline \multirow[t]{2}{*}{ Monthly income } & $5000 \mathrm{SR}$ & 104 & 40.3 & 92 & 39.3 & \\
\hline & $\begin{array}{l}5000- \\
10000 \mathrm{SR}\end{array}$ & 71 & 27.5 & 67 & 28.6 & 0.952 \\
\hline
\end{tabular}




\begin{tabular}{|c|c|c|c|c|c|c|}
\hline & & \multicolumn{2}{|c|}{$\begin{array}{l}\text { High smartphone use } \\
\text { group (261) }\end{array}$} & \multicolumn{2}{|c|}{$\begin{array}{l}\text { Low smartphone use } \\
\text { group (251) }\end{array}$} & \multirow[t]{2}{*}{$\begin{array}{l}P \\
\text { value }\end{array}$} \\
\hline & $\begin{array}{l}10000- \\
20000 \mathrm{SR}\end{array}$ & 69 & 26.7 & 60 & 25.6 & \\
\hline & $\begin{array}{l}>20000 \\
\text { SR }\end{array}$ & 14 & 5.4 & 15 & 6.4 & \\
\hline \multirow{4}{*}{$\begin{array}{l}\text { Monthly income for father } \\
\text { or mother or both }\end{array}$} & $5000 \mathrm{SR}$ & 79 & 30.5 & 60 & 25.1 & \multirow[t]{4}{*}{0.425} \\
\hline & $\begin{array}{l}5000- \\
10000 \mathrm{SR}\end{array}$ & 59 & 22.8 & 54 & 22.6 & \\
\hline & $\begin{array}{l}10000- \\
20000 \mathrm{SR}\end{array}$ & 77 & 29.7 & 73 & 30.5 & \\
\hline & $\begin{array}{l}>20000 \\
\text { SR }\end{array}$ & 44 & 17.0 & 52 & 21.8 & \\
\hline
\end{tabular}

The PHQ-9 questionnaire for depression showed a significant association between high smartphone use and MDD ( $r=0.408)(p=0.001)$ (Table 4$) ; 65.9 \%$ of participants with high smartphone use had no depression, while $10.3 \%$ had severe depression, $16.1 \%$ had moderately severe depression, and $7.7 \%$ of the participants had moderate depression. $81.7 \%$ of the non-smartphone addiction group showed no depression symptoms, while $6.0 \%$ showed severe depression, $4.4 \%$ showed moderately severe depression, and $8.0 \%$ showed moderate depression. Multivariate analysis showed an elevated risk of simultaneously having severe depression and smartphone addiction $(\mathrm{OR}=3.779)(\mathrm{P}=0.001)(\mathrm{Table} 2)$ (Table 5). In conclusion, high smartphone use is associated with a higher prevalence of depression. [Table 4][Table 5] 
Table 4

Relation between smartphone addiction and Smoking, Depression, Insomnia, Physical Activity and ADHD symptoms.

\begin{tabular}{|c|c|c|c|c|c|c|}
\hline & & \multicolumn{2}{|c|}{$\begin{array}{l}\text { Smartphone } \\
\text { addiction }\end{array}$} & \multicolumn{2}{|c|}{$\begin{array}{l}\text { No smartphone } \\
\text { addiction }\end{array}$} & $P$ value \\
\hline & & Number & $\%$ & Number & $\%$ & \multirow[t]{7}{*}{$0.039 *$} \\
\hline \multirow[t]{6}{*}{ Smoking } & Yes & 22 & 8.4 & 31 & 12.4 & \\
\hline & low independence & 7 & 2.7 & 20 & 8.0 & \\
\hline & $\begin{array}{l}\text { low to mod } \\
\text { independence }\end{array}$ & 6 & 2.3 & 4 & 1.6 & \\
\hline & moderate independence & 7 & 2.7 & 6 & 2.4 & \\
\hline & high independence & 2 & .8 & 1 & .4 & \\
\hline & No Smoking & 239 & 91.6 & 220 & 87.6 & \\
\hline \multirow[t]{4}{*}{ Depression } & Moderate depression & 20 & 7.7 & 20 & 8.0 & \multirow[t]{4}{*}{$0.013^{*}$} \\
\hline & $\begin{array}{l}\text { Moderately severe } \\
\text { depression }\end{array}$ & 42 & 16.1 & 11 & 4.4 & \\
\hline & Severe depression & 27 & 10.3 & 15 & 6.0 & \\
\hline & No Depression & 172 & 65.9 & 205 & 81.7 & \\
\hline Insomnia & insomnia & 151 & 65.7 & 99 & 44.4 & \multirow{2}{*}{$\hat{0.001 *}$} \\
\hline \multirow{3}{*}{$\begin{array}{l}\text { ADHD } \\
\text { symptoms }\end{array}$} & no insomnia & 79 & 34.3 & 124 & 55.6 & \\
\hline & have ADHD symptoms & 110 & 47.8 & 44 & 19.7 & \multirow{2}{*}{$<.001 *$} \\
\hline & $\begin{array}{l}\text { have not ADHD } \\
\text { symptoms }\end{array}$ & 120 & 52.2 & 179 & 80.3 & \\
\hline
\end{tabular}


Table 5

Multivariate associations between Smoking, Depression, Insomnia, with ADHD symptoms with smartphone addiction

\begin{tabular}{|c|c|c|c|c|c|}
\hline & & Odds ratio & $95 \% \mathrm{Cl}$ & & $P$ value \\
\hline & & & Lower & Upper & \\
\hline Depression & Clinically significant depression & 1.261 & 0.562 & 2.829 & 0.574 \\
\hline & Moderately severe depression & 1.43 & 0.508 & 4.023 & 0.498 \\
\hline & Severe depression & 3.779 & 1.317 & 10.846 & $0.013^{*}$ \\
\hline & No Depression ${ }^{* *}$ & 1 & & & \\
\hline Insomnia & insomnia & 2.113 & 1.372 & 3.255 & $0.001^{\star}$ \\
\hline & no insomnia* & 1 & & & \\
\hline ADHD symptoms & have ADHD symptoms & 2.712 & 1.682 & 4.374 & $<0.001^{*}$ \\
\hline & have not ADHD symptoms ${ }^{\star *}$ & 1 & & & \\
\hline
\end{tabular}

We used the Fagerstrom Test to assess nicotine dependence. The total result showed a moderate positive significant Pearson Correlation coefficient between smartphone addiction and smoking $(r=0.323)(p=$ 0.018). $20.8 \%$ of our population are active smokers, $8.4 \%$ of those with smartphone addiction were smokers, which means that $41.5 \%$ of smokers were addicted to smartphones $(p=0.039)$. (Table 4$)$

We measured Sleep difficulty by using Athens Insomnia Scale (AIS); it showed a significant correlation between the severity of insomnia and smartphone use $(r=0.306)(p=0.001)$ (Table 4$) ; 65.7 \%$ of those with high smartphone use had insomnia, and $34.3 \%$ did not. On the other hand, only $44.4 \%$ of the nonsmartphone addiction group had insomnia while $55.6 \%$ free of it, which showcases a higher prevalence of insomnia among high smartphone users. Smartphone addicts have about two times the risk of developing insomnia $(\mathrm{OR}=2.113)(\mathrm{P}=0.013)($ Table 5).

We applied the Adult ADHD Self-Report Scale (ASRS-v1.1) symptom checklist to consider ADHD symptoms. $47.8 \%$ of high smartphone use participants had ADHD symptoms. On the other hand, $19.7 \%$ of the non-smartphone addiction group showed ADHD symptoms, indicating a significant relationship between smartphone addiction and Adult ADHD symptoms $(r=0.405)(p=0.001)$ (Table 4). Those who were addicted to smartphone use had a significant risk of developing ADHD symptoms $(O R=2.712)(P<$ 0.001) (Table 5).

\section{Discussion:}


Our study reveals that $51 \%$ of our population scored high on the SAS. In a similar study in Lebanon, they used the Smartphone Addiction Inventory and found that $49 \%$ of university students had smartphone addiction ${ }^{9}$, while another study in Saudi Arabia found that $61 \%$ of university students had high smartphone use ${ }^{3}$.

We found a significant relationship between age and smartphone addiction, A study in Turkey suggested that gender and young age were independent factors for smartphone use. Women and younger populations may, therefore, be at higher risk for smartphone addiction ${ }^{14}$ however, our results show no significant relationship between gender and smartphone addiction. Reaffirming previous literature, we have found a significant positive relationship between smartphone addiction and MDD; research has consistently shown a similar association ${ }^{2,55,23}$. In a review of 23 studies, it was found that depression is a consistent variable associated with smartphone use ${ }^{15}$. A study on Korean adolescents found an association between unhealthful lifestyle habits and smartphone addiction, linking unhealthy diets, weight gain, and sleep disturbances to smartphone addiction, which are also considered to be symptoms and consequences of $\mathrm{MD}^{35}$. A study done to university students in Saudi Arabia, showcased that $43 \%$ of problematic smartphone users were found to have reduced sleeping hours ${ }^{3}$. Our current research indicates that there is a strong association between the use of smartphones and insomnia, where most of our subjects (65.7\%) reported insomnia and high usage of smartphones. Intensive smartphone use was shown to be positively correlated with poor sleep quality, and daytime sleepiness, which was consistent with our findings ${ }^{53}$. In another study conducted at King Abdul-Aziz University, Jeddah, showed that mobile use was highly prevalent among participants (73.4\% used them $>5 \mathrm{~h} /$ day), where two-thirds of participants had poor sleep quality and latency to sleep ${ }^{29}$. A Belgian study revealed that bedtime smartphone use indicated later self-reported rise time, higher insomnia score and increased fatigue ${ }^{17}$. A study on students between the ages of 18 and 39 indicated that insomnia is associated with phone use $^{22}$. The National sleep foundation's 2011 sleep in America poll showed results indicating that use of numerous technological devices before bedtime would lead to difficulty falling asleep ${ }^{26}$. Confirming our finding of a higher prevalence of ADHD symptoms among those with smartphone addiction (47.8\%) compared to low-use smartphone users (19.7\%); An epidemiological study done on 4512 south korean adolescents using SAS examined the relationship between Smartphone addiction and symptoms of depression, anxiety and ADHD found that those with smartphone addiction had a higher likelihood of having ADHD symptoms ${ }^{36}$. Studies have found similarities between Smartphone Addiction and Internet Addiction $(I A)^{6}$. A study comparing smartphone addiction and IA, using 12 addiction risk factors, found that there are several similar risk factors, such as depression, anxiety, self-control, life satisfaction, and aggression; the effects of the five identified addiction psychological factors were all significant $(P<0.01)$ for both IA and smartphone addiction ${ }^{31}$. Current results have shown a relationship between behavioral addictions and adult ADHD. A previous similar study looked at the relationship between Internet addiction (IA) and symptoms of ADHD severity and emotional distress through an online survey established a significant relationship between the severity of IA symptoms and the presence and severity of ADHD symptoms ${ }^{16}$. furthermore, Studies showed that individuals with ADHD are more likely to develop other 
types of behavioral addictions, such as gambling disorders ${ }^{10,19}$. Adult ADHD is strongly associated with substance use disorder in a literature review of Adult ADHD in the Arab World ${ }^{27}$.

\section{Limitations:}

Due to the nature of cross-sectional studies representing a single point of time rather than a longitudinal observation, it is therefore not guaranteed to be representative of the population. This research cannot be used to analyze the behavior of the population over a period of time. Cross-sectional studies do not specify the cause of the disease. There is also a chance of recall bias on the part of participants. Since our study has been circulated online, through emails and various social media channels, it excludes people who develop MDD, Insomnia, and ADHD who do not have access to social media, or who are not interested in taking part in our questionnaire due to social stigma. Therefore, future research should involve participants who are more open to the idea of mental health and mental illness. Besides, while PHQ-9 is the most commonly used questionnaire for the diagnosis of MDD in clinical practice, it contains somatic symptoms such as exhaustion and poor appetite that can be attributed to other diseases, thereby placing the study at risk of overestimating MDD prevalence.

\section{Conclusion:}

In Conclusion, due to the ease of access and the utter dependence of smartphones in our daily lives, their mental and physical impacts should be studied across different populations. The post-graduate student population is underrepresented throughout the medical literature, and we hope to extend the knowledge regarding post-graduate students to include smartphone addiction. Confirming several studies, we found a positive association between Insomnia, Depression, Adult ADHD, and Smartphone overuse. Therefore, we encourage the scientific community to study the impacts of smartphone addiction and the mental health of post-graduate students.

Finally, we recommend that smartphone addiction be carefully monitored for post-graduate students displaying Depression, Insomnia, or ADHD.

\section{Declarations:}

\section{Conflict of Interest:}

Dr. Mclntyre reports grants from Stanley Medical Research Institute, and from CIHR/GACD/Chinese National Natural Research Foundation. and other relationships that may include consultations/speaker fees, from Lundbeck, Janssen, Shire, Purdue, Pfizer, Otsuka, Allergan, Takeda, Neurocrine, Sunovion, Minerva outside the submitted work.

All other authors declare that they have no conflicts of interest. 


\section{Funding:}

This research was supported by the Deanship of Scientific Research, Al-Imam Mohammad Ibn Saud Islamic University (IMSIU), Saudi Arabia.

\section{Consent to publication:}

Not Applicable.

\section{Availability of Data and Materials:}

The datasets analyzed during the current study available from the corresponding author on reasonable request.

\section{Contribution:}

Conception and design of study was done by A. Alageel, R. Alyahya, R. Alghamdi and R. Mclntyre. Acquisition of data was done by A. Alageel, R. Alyahya, Y. Bahatheq. Analysis and/or interpretation of data was done by A. Alageel, R. Alyahya, N. Alrahili and M. lacobucci. A. Alageel, R. Alyahya, R. Alghamdi, Y. Bahatheq and N. Alzunaydi wrote the main manuscript and prepared the tables. All authors reviewed the manuscript

\section{Acknowledgements:}

We would like to express our sincere gratitude to the Deanship of Academic Research, Al-Imam Mohammad Ibn Saud Islamic University (IMSIU), and SABIC Psychological Health Research \& Applications Chair (SPHRAC).

\section{Ethics Approval and consent to participate:}

In accordance with the WMA Declaration of Helsinki guidelines and the Vancouver protocol, this study was approved by the Institutional Review Board (IRB) of Imam Mohammad ibn Saud Islamic University in Riyadh, Saudi Arabia.

Informed consent was obtained from all participants through a statement of agreement at the beginning of each questionnaire. Ensuring the protection of the privacy of research subjects and the confidentiality of their personal information. each subject was adequately informed of the aims, methods, sources of funding, any possible conflicts of interest, institutional affiliations of the researcher, the anticipated benefits and potential risks of the study and the discomfort it may entail, post-study provisions, and all 
other relevant aspects of the study; in accordance with the WMA Declaration of Helsinki guidelines and the Vancouver protocol.

\section{References:}

1. Alhadi, A. N., Alateeq, D. A., Al-Sharif, E., Bawazeer, H. M., Alanazi, H., Alshomrani, A. T., ... Alowaybil, R. (2017). An arabic translation, reliability, and validation of Patient Health Questionnaire in a Saudi sample. Annals of General Psychiatry, 16(1). https://doi.org/10.1186/s12991-017-0155-1

2. Alhassan, A. A., Alqadhib, E. M., Taha, N. W., Alahmari, R. A., Salam, M., \& Almutairi, A. F. (2018). The relationship between addiction to smartphone usage and depression among adults: a cross sectional study. BMC Psychiatry, 18(1). https://doi.org/10.1186/s12888-018-1745-4

3. Alosaimi, F., Alyahya, H., Alshahwan, H., Mahyijari, N. A., \& Shaik, S. (2016). Smartphone addiction among university students in Riyadh, Saudi Arabia. Saudi Medical Journal, 37(6), 675-683. https://doi.org/10.15537/smj.2016.6.14430

4. American Psychiatric Association (2013). Diagnostic and Statistical Manual of Mental Disorders. https://doi.org/10.1176/appi.books.9780890425596

5. Batstra, L., \& Frances, A. (2012). DSM-5 Further Inflates Attention Deficit Hyperactivity Disorder. The Journal of Nervous and Mental Disease, 200(6), 486-488. https://doi.org/10.1097/nmd.0b013e318257c4b6

6. Ben-Yehuda, L., Greenberg, L., \& Weinstein, A. (2016). Internet Addiction by Using the SmartphoneRelationships between Internet Addiction, Frequency of Smartphone Use and the State of Mind of Male and Female Students. Journal of Reward Deficiency Syndrome and Addiction Science, 2(1). https://doi.org/10.17756/jrdsas.2016-024

7. Block, J. J. (2008). Issues for DSM-V: Internet Addiction. American Journal of Psychiatry, 165(3), 306-307. https://doi.org/10.1176/appi.ajp.2007.07101556

8. Boden, J. M., \& Fergusson, D. M. (2011). Alcohol and depression. Addiction, 106(5), 906-914. https://doi.org/10.1111/j.1360-0443.2010.03351.x

9. Boumosleh, J. M., \& Jaalouk, D. (2017). Depression, anxiety, and smartphone addiction in university students- A cross sectional study. Plos One, 12(8). https://doi.org/10.1371/journal.pone.0182239

10. Brandt, L., \& Fischer, G. (2017). Adult ADHD Is Associated With Gambling Severity and Psychiatric Comorbidity Among Treatment-Seeking Problem Gamblers. Journal of Attention Disorders,23(12), 1383-1395. doi:10.1177/1087054717690232

11. Campbell, W. G. (2003). Addiction: A Disease of Volition Caused by a Cognitive Impairment. The Canadian Journal of Psychiatry, 48(10), 669-674. https://doi.org/10.1177/070674370304801005

12. Chen, L., Wang, L., Qiu, X. H., Yang, X. X., Qiao, Z. X., Yang, Y. J., \& Liang, Y. (2013). Depression among Chinese University Students: Prevalence and Socio-Demographic Correlates. PLOS ONE, 8(3). https://doi.org/10.1371/journal.pone.0058379 
13. Cornelius, J. R. (1997). Fluoxetine in Depressed Alcoholics. Archives of General Psychiatry, 54(8), 700. https://doi.org/10.1001/archpsyc.1997.01830200024004

14. Demirci, K., Akgönül, M., \& Akpinar, A. (2015). Relationship of smartphone use severity with sleep quality, depression, and anxiety in university students. Journal of Behavioral Addictions, 4(2), 85-92. https://doi.org/10.1556/2006.4.2015.010

15. Elhai, J. D., Dvorak, R. D., Levine, J. C., \& Hall, B. J. (2017). Problematic smartphone use: A conceptual overview and systematic review of relations with anxiety and depression psychopathology. Journal of Affective Disorders, 207, 251-259. https://doi.org/10.1016/j.jad.2016.08.030

16. Evren, B., Evren, C., Dalbudak, E., Topcu, M., \& Kutlu, N. (2018). Relationship of internet addiction severity with probable ADHD and difficulties in emotion regulation among young adults. Psychiatry Research, 269, 494-500. https://doi.org/10.1016/j.psychres.2018.08.112

17. Exelmans, L., \& Bulck, J. V. (2016). Bedtime mobile phone use and sleep in adults. Social Science \& Medicine, 148, 93-101. doi:10.1016/j.socscimed.2015.11.037

18. Faraone, S. V., Biederman, J., Spencer, T., Wilens, T., Seidman, L. J., Mick, E., \& Doyle, A. E. (2000). Attention-deficit/hyperactivity disorder in adults: an overview. Biological Psychiatry, 48(1), 9-20. https://doi.org/10.1016/s0006-3223(00)00889-1

19. Fatséas, M., Hurmic, H., Serre, F., Debrabant, R., Daulouède, J.-P., Denis, C., \& Auriacombe, M. (2016). Addiction severity pattern associated with adult and childhood Attention Deficit Hyperactivity Disorder (ADHD) in patients with addictions. Psychiatry Research, 246, 656-662. https://doi.org/10.1016/j.psychres.2016.10.071

20. Fayyad, J., Graaf, R. D., Kessler, R., Alonso, J., Angermeyer, M., Demyttenaere, K., ... Jin, R. (2007). Cross-national prevalence and correlates of adult attention-deficit hyperactivity disorder. British Journal of Psychiatry, 190(5), 402-409. https://doi.org/10.1192/bjp.bp.106.034389

21. Foddy, B., \& Savulescu, J. (2010). Relating Addiction to Disease, Disability, Autonomy, and the Good Life. Philosophy, Psychiatry, \& Psychology, 17(1), 35-42. https://doi.org/10.1353/ppp.0.0284

22. Fossum, I. N., Nordnes, L. T., Storemark, S. S., Bjorvatn, B., \& Pallesen, S. (2013). The Association Between Use of Electronic Media in Bed Before Going to Sleep and Insomnia Symptoms, Daytime Sleepiness, Morningness, and Chronotype. Behavioral Sleep Medicine, 12(5), 343-357. https://doi.org/10.1080/15402002.2013.819468

23. Gao, T., Xiang, Y.-T., Zhang, H., Zhang, Z., \& Mei, S. (2017). Neuroticism and quality of life: Multiple mediating effects of smartphone addiction and depression. Psychiatry Research, 258, 457-461. https://doi.org/10.1016/j.psychres.2017.08.074

24. Goodman, A. (1990). Addiction: definition and implications. Addiction, 85(11), 1403-1408. https://doi.org/10.1111/j.1360-0443.1990.tb01620.x

25. Google I/O Developer Conference, 2019

26. Gradisar, M., Wolfson, A. R., Harvey, A. G., Hale, L., Rosenberg, R., \& Czeisler, C. A. (2013). The Sleep and Technology Use of Americans: Findings from the National Sleep Foundation's 2011 Sleep in 
America Poll. Journal of Clinical Sleep Medicine, 09(12), 1291-1299.

https://doi.org/10.5664/jcsm.3272

27. Hayek, G. E., Saab, D., Farhat, C., Krayem, Z., \& Karam, E. (2019). Adult ADHD in the Arab World: A review. Archives of Psychology, 3(7). https://doi.org/10.31296/aop.v3i7.115

28. Haynes, P. L., Parthasarathy, S., Kersh, B., \& Bootzin, R. R. (2011). Examination of insomnia and insomnia treatment in psychiatric inpatients. International Journal of Mental Health Nursing, 20(2), 130-136. https://doi.org/10.1111/j.1447-0349.2010.00711.x

29. Ibrahim, N. K., Baharoon, B. S., Banjar, W. F., Jar, A. A., Ashor, R. M., Aman, A. A., \& Al-Ahmadi, J. R. (2018). Mobile Phone Addiction and Its Relationship to Sleep Quality and Academic Achievement of Medical Students at King Abdulaziz University, Jeddah, Saudi Arabia. Journal of research in health sciences, 18(3), e00420.

30. Jacobs, D. F. (1986). A general theory of addictions: A new theoretical model. Journal of Gambling Behavior, 2(1), 15-31. https://doi.org/10.1007/bf01019931

31. Jeong, Y. J., Suh, B., \& Gweon, G. (2019). Is smartphone addiction different from Internet addiction? comparison of addiction-risk factors among adolescents. Behaviour \& Information Technology, 39(5), 578-593. https://doi.org/10.1080/0144929x.2019.1604805

32. Kassim, S., Salam, M., \& Croucher, R. (2012). Validity and Reliability of the Fagerstrom Test for Cigarette Dependence in a Sample of Arabic Speaking UK-Resident Yemeni Khat Chewers. Asian Pacific Journal of Cancer Prevention, 13(4), 1285-1288.

https://doi.org/10.7314/apjcp.2012.13.4.1285

33. Kessler, R. C. (1994). Lifetime and 12-Month Prevalence of DSM-III-R Psychiatric Disorders in the United States. Archives of General Psychiatry, 51(1), 8.

https://doi.org/10.1001/archpsyc.1994.03950010008002

34. Kessler, R. C., Adler, L., Ames, M., Demler, O., Faraone, S., Hiripi, E., ... Walters, E. E. (2005). The World Health Organization adult ADHD self-report scale (ASRS): a short screening scale for use in the general population. Psychological Medicine, 35(2), 245-256.

https://doi.org/10.1017/s0033291704002892

35. Kim, Y.-J., Jang, H., Lee, Y., Lee, D., \& Kim, D.-J. (2018). Effects of Internet and Smartphone Addictions on Depression and Anxiety Based on Propensity Score Matching Analysis. International Journal of Environmental Research and Public Health, 15(5), 859. https://doi.org/10.3390/ijerph15050859

36. Kim, S., Park, J., Kim, H., Pan, Z., Lee, Y., \& Mcintyre, R. S. (2019). The relationship between smartphone addiction and symptoms of depression, anxiety, and attention-deficit/hyperactivity in South Korean adolescents. Annals of General Psychiatry,18(1). doi:10.1186/s12991-019-0224-8

37. Kroenke, K., Spitzer, R. L., \& Williams, J. B. (2001). The PHQ-9. Journal of General Internal Medicine, 16(9), 606-613. doi:10.1046/j.1525-1497.2001.016009606.x

38. Kumar, S., Kumar, A., Badiyani, B., Singh, S. K., Gupta, A., \& Ismail, M. B. (2018). Relationship of Internet Addiction With Depression And Academic Performance In Indian Dental Students. Medicine and Pharmacy Reports, 91(3), 300-306. https://doi.org/10.15386/cjmed-796 
39. Kwon, M., Kim, D.-J., Cho, H., \& Yang, S. (2013). The Smartphone Addiction Scale: Development and Validation of a Short Version for Adolescents. PLOS ONE, 8(12).

https://doi.org/10.1371/journal.pone.0083558

40. Maestri, L. (2019). Financial Times. other, Financial Times. https://www.ft.com.

41. Marks, I. (1990). Behavioural (non-chemical) addictions. Addiction, 85(11), 1389-1394. https://doi.org/10.1111/j.1360-0443.1990.tb01618.x

42. Mcintyre, R. S., Cha, D. S., Soczynska, J. K., Woldeyohannes, H. O., Gallaugher, L. A., Kudlow, P., ... Baskaran, A. (2013). Cognitive Deficits And Functional Outcomes In Major Depressive Disorder: Determinants, Substrates, And Treatment Interventions. Depression and Anxiety, 30(6), 515-527. https://doi.org/10.1002/da.22063

43. Nordenfelt, L. (2010). On Concepts and Theories of Addiction. Philosophy, Psychiatry, \& Psychology, 17(1), 27-30. https://doi.org/10.1353/ppp.0.0271

44. Orford, J. (2001). Addiction as excessive appetite. Addiction, 96(1), 15-31. https://doi.org/10.1046/j.1360-0443.2001.961152.x

45. Pfeifer, T. A., Kranz, P. L., \& Scoggin, A. E. (2008). Perceived stress in occupational therapy students. Occupational Therapy International, 15(4), 221-231. https://doi.org/10.1002/oti.256

46. Quello, S., Brady, K., \& Sonne, S. (2005). Mood Disorders and Substance Use Disorder: A Complex Comorbidity. Science \& Practice Perspectives, 3(1), 13-21. https://doi.org/10.1151/spp053113

47. Regier, D. A. (1990). Comorbidity of Mental Disorders With Alcohol and Other Drug Abuse. Jama, 264(19), 2511. https://doi.org/10.1001/jama.1990.03450190043026

48. Robinson, T. E., \& Berridge, K. C. (2001). Incentive-sensitization and addiction. Addiction, 96(1), 103114. https://doi.org/10.1046/j.1360-0443.2001.9611038.x

49. Robinson, T. E., \& Berridge, K. C. (2008). The incentive sensitization theory of addiction: some current issues. Philosophical Transactions of the Royal Society B: Biological Sciences, 363(1507), 31373146. https://doi.org/10.1098/rstb.2008.0093

50. Scalo, J., Desai, P., \& Rascati, K. (2014). Insomnia, hypnotic use, and health-related quality of life in a nationally representative sample. Quality of Life Research, 24(5), 1223-1233. https://doi.org/10.1007/s11136-014-0842-1

51. Sfendla, A., Laita, M., Nejjar, B., Souirti, Z., Touhami, A. A. O., \& Senhaji, M. (2018). Reliability of the Arabic Smartphone Addiction Scale and Smartphone Addiction Scale-Short Version in Two Different Moroccan Samples. Cyberpsychology, Behavior, and Social Networking, 21(5), 325-332. https://doi.org/10.1089/cyber.2017.0411

52. Soldatos, C. R., Dikeos, D. G., \& Paparrigopoulos, T. J. (2003). The diagnostic validity of the Athens Insomnia Scale. Journal of Psychosomatic Research, 55(3), 263-267. https://doi.org/10.1016/s0022-3999(02)00604-9

53. Spagnoli, Balducci, Fabbri, Molinaro, \& Barbato. (2019). Workaholism, Intensive Smartphone Use, and the Sleep-Wake Cycle: A Multiple Mediation Analysis. International Journal of Environmental Research and Public Health, 16(19), 3517. https://doi.org/10.3390/ijerph16193517 
54. Sussman, S., \& Sussman, A. N. (2011). Considering the Definition of Addiction. International Journal of Environmental Research and Public Health, 8(10), 4025-4038. https://doi.org/10.3390/ijerph8104025

55. Yen, C.-F., Tang, T.-C., Yen, J.-Y., Lin, H.-C., Huang, C.-F., Liu, S.-C., \& Ko, C.-H. (2009). Symptoms of problematic cellular phone use, functional impairment and its association with depression among adolescents in Southern Taiwan. Journal of Adolescence, 32(4), 863-873. https://doi.org/10.1016/j.adolescence.2008.10.006 